Supporting Information

\title{
Porous Carbon-Supported Gold Nanoparticles for Oxygen Reduction Reaction: Effects of Nanoparticle Size
}

\author{
Likai Wang, ${ }^{\text {a } Z h e n g h u a ~ T a n g, ~}{ }^{*, a, b}$ Wei Yan, ${ }^{a}$ Hongyu Yang, ${ }^{a}$ Qiannan Wang, ${ }^{a}$ and Shaowei \\ Chen*, a,c
}

${ }^{a}$ New Energy Research Institute, School of Environment and Energy, South China University of Technology, Guangzhou Higher Education Mega Centre, Guangzhou, 510006, P. R. China. Email: zhht@scut.edu.cn.

${ }^{b}$ Guangdong Provincial Key Laboratory of Atmospheric Environment and Pollution Control, South China University of Technology, Guangzhou Higher Education Mega Centre, Guangzhou, 510006, P. R. China

${ }^{c}$ Department of Chemistry and Biochemistry, University of California, 1156 High Street, Santa Cruz, California 95064, United States. Email: shaowei@ucsc.edu

\section{Preparation of porous carbons}

Porous carbons were prepared by following a previous synthetic method. ${ }^{1}$ Firstly, an aqueous solution was prepared by dissolving $1.25 \mathrm{~g}$ of sucrose and $0.14 \mathrm{~g}$ of $\mathrm{H}_{2} \mathrm{SO}_{4}$ in $5 \mathrm{~mL}$ of $\mathrm{H}_{2} \mathrm{O}$ in a $50 \mathrm{~mL}$ Telfon-lined autoclave, and $1 \mathrm{~g}$ of SBA-15 amorphous silica was then added into the above aqueous solution. The mixture was under magnetic stirring for $2 \mathrm{~h}$ at room temperature, followed by heating at $100{ }^{\circ} \mathrm{C}$ for $6 \mathrm{~h}$ in an oven and at $160{ }^{\circ} \mathrm{C}$ for another $6 \mathrm{~h}$. The precursor turned dark brown during the heating treatment in the oven. Secondly, the resultant precursor was again heated following the above procedure after the addition of $0.8 \mathrm{~g}$ sucrose, $0.09 \mathrm{~g} \mathrm{H}_{2} \mathrm{SO}_{4}$ and $5 \mathrm{~g} \mathrm{H}_{2} \mathrm{O}$. Finally, the obtained precursor underwent pyrolysis at $900{ }^{\circ} \mathrm{C}$ for $5 \mathrm{~h}$ under a $\mathrm{N}_{2}$ flow, affording the preparation of carbon-silica composites, which were immersed in a $10 \mathrm{wt} \% \mathrm{HF}$ solution for $24 \mathrm{~h}$ to remove the silica template, affording porous carbon which displayed ordered trenches of $c a .5-6 \mathrm{~nm}$ in diameter and several microns in length. ${ }^{2}$ As shown in Figure S1-S2.

\section{Synthesis of $\mathrm{Au}_{25}\left(\mathrm{SC}_{2} \mathrm{H}_{4} \mathrm{Ph}\right)_{18}$}

$\mathrm{Au}_{25}$ nanoclusters were prepared by adopting a previously reported approach. ${ }^{3}$ Briefly, $1 \mathrm{mmol}$ $\mathrm{HAuCl}_{4} \cdot 4 \mathrm{H}_{2} \mathrm{O}$ and $1 \mathrm{mmol}$ TOAB were co-dissolved in $30 \mathrm{~mL}$ THF in a $100 \mathrm{~mL}$ of round-bottom flask, and the resulting solution was cooled to $0{ }^{\circ} \mathrm{C}$ in an ice bath over a period of $30 \mathrm{~min} .6 \mathrm{mmol}$ of $\mathrm{PhCH}_{2} \mathrm{CH}_{2} \mathrm{SH}$ was slowly added to the flask; the speed of stirring was turned to be very low (60 rpm) until the red color solution turned colorless in $\sim 3 \mathrm{~h}$. Then, the stirring speed was increased to $1100 \mathrm{rpm}$, and an aqueous solution of $\mathrm{NaBH}_{4}(10 \mathrm{mmol}$ freshly dissolved with $5 \mathrm{~mL}$ ice-cold nanopure water) was rapidly added all at once. The reaction was under vigorous stirring for $12 \mathrm{~h}$. After removal of some precipitates (by-products), the solution was concentrated by rotary evaporation. Then cold water was added, and the precipitates were collected and thoroughly washed with methanol for five times to remove excess thiol. The as-obtained solids were the $\mathrm{Au}_{25}\left(\mathrm{SC}_{2} \mathrm{H}_{4} \mathrm{Ph}\right)_{18}$ nanoclusters.

\section{Synthesis of $\mathrm{Au}_{38}\left(\mathrm{SC}_{2} \mathrm{H}_{4} \mathrm{Ph}\right)_{24}$}

$\mathrm{Au}_{38}$ nanoclusters were prepared according to a previously reported method. ${ }^{4}$ Firstly, $196.9 \mathrm{mg}$ of $\mathrm{HAuCl}_{4} \cdot 3 \mathrm{H}_{2} \mathrm{O}$ and $614 \mathrm{mg}$ of glutathione (GSH) were vigorously stirred at room temperature for $30 \mathrm{~min}$ in $20 \mathrm{~mL}$ acetone, then the mixture was cooled to $\sim 0^{\circ} \mathrm{C}$ in an ice bath over a period of $20 \mathrm{~min}$. Subsequently, a freshly prepared aqueous solution of $\mathrm{NaBH}_{4}(5 \mathrm{mmol}$, dissolved with $6 \mathrm{~mL}$ ice-cold nanopure water) was 
rapidly added into the suspension under vigorous stirring. After 20 min, black $\mathrm{Au}_{\mathrm{n}}(\mathrm{SG})_{\mathrm{m}}$ nanoparticles were precipitated out of the solution. The clear acetone supernatant was removed, and the polydisperse $\mathrm{Au}_{\mathrm{n}}(\mathrm{SG})_{\mathrm{m}}$ nanoparticles were dissolved with $7 \mathrm{~mL}$ nanopure water, and mixed with $0.4 \mathrm{~mL}$ ethanol, $2 \mathrm{~mL}$ toluene and $2 \mathrm{~mL} \mathrm{PhC}_{2} \mathrm{H}_{4} \mathrm{SH}$ in a $25 \mathrm{~mL}$ of round-bottom flask under vigorous stirring at ambient temperature for $1 \mathrm{~h}$. Then the biphase solution was heated to $80^{\circ} \mathrm{C}$ and kept at this temperature for $\sim 40 \mathrm{~h}$. The organic phase was washed with methanol for five times to remove excess thiol, and $\mathrm{Au}_{38}\left(\mathrm{SC}_{2} \mathrm{H}_{4} \mathrm{Ph}\right)_{24}$ nanoclusters were separated by extraction with dichloromethane.

\section{Synthesis of $\mathrm{Au}_{144}\left(\mathrm{SC}_{2} \mathrm{H}_{4} \mathrm{Ph}\right)_{60}$}

$\mathrm{Au}_{144}$ nanoclusters were prepared in reference to a previous method. ${ }^{5}$ Typically, $196.9 \mathrm{mg}$ of $\mathrm{HAuCl}_{4} \cdot 3 \mathrm{H}_{2} \mathrm{O}$ was dissolved in $6 \mathrm{~mL}$ nanopure water, and $314.6 \mathrm{mg}$ of TOAB was dissolved in $10 \mathrm{~mL}$ toluene. These two solutions were mixed in a $25 \mathrm{~mL}$ of round-bottom flask under vigorous stirring at room temperature for $30 \mathrm{~min}$. The clear aqueous phase was removed with a separatory funnel. The toluene solution containing $\mathrm{Au}$ (III) was cooled to $\sim 0{ }^{\circ} \mathrm{C}$ in an ice bath over a period of $30 \mathrm{~min}$. Then, $0.206 \mathrm{~mL}$ of $\mathrm{PhCH}_{2} \mathrm{CH}_{2} \mathrm{SH}$ was added under vigorous stirring. The deep red solution turned colorless after $\sim 2 \mathrm{~h}$. An aqueous solution of $\mathrm{NaBH}_{4}(5 \mathrm{mmol}$, dissolved in $6 \mathrm{~mL}$ ice-cold nanopure water) was rapidly added to the flask all at once under vigorous stirring. The reaction was allowed to proceed for $\sim 24 \mathrm{~h}$. Then, the aqueous phase was discarded and the black toluene phase was dried by rotary evaporation. The Au nanoparticles were separated by ethanol from TOAB and other side products. Then, excess $\mathrm{PhCH}_{2} \mathrm{CH}_{2} \mathrm{SH}$ was used to etch the as-prepared $\mathrm{Au}$ nanoparticles. Generally, $80 \mathrm{mg} \mathrm{Au}$ nanoparticles were dissolved with $4 \mathrm{~mL}$ toluene, and $2 \mathrm{~mL} \mathrm{PhCH}_{2} \mathrm{CH}_{2} \mathrm{SH}$ was added to the solution. The mixture solution was heated at $80{ }^{\circ} \mathrm{C}$ for $24 \mathrm{~h}$ under constant stirring. After that, $80 \mathrm{~mL}$ methanol was added to the solution to precipitate $\mathrm{Au}$ nanoparticles. Only $\mathrm{Au}_{144}$ nanoclusters and $\mathrm{Au}(\mathrm{I})-\mathrm{SCH}_{2} \mathrm{CH}_{2} \mathrm{Ph}$ existed in the black precipitation. $\mathrm{Au}_{144}$ nanoclusters were extracted with dichloromethane as the final product. 

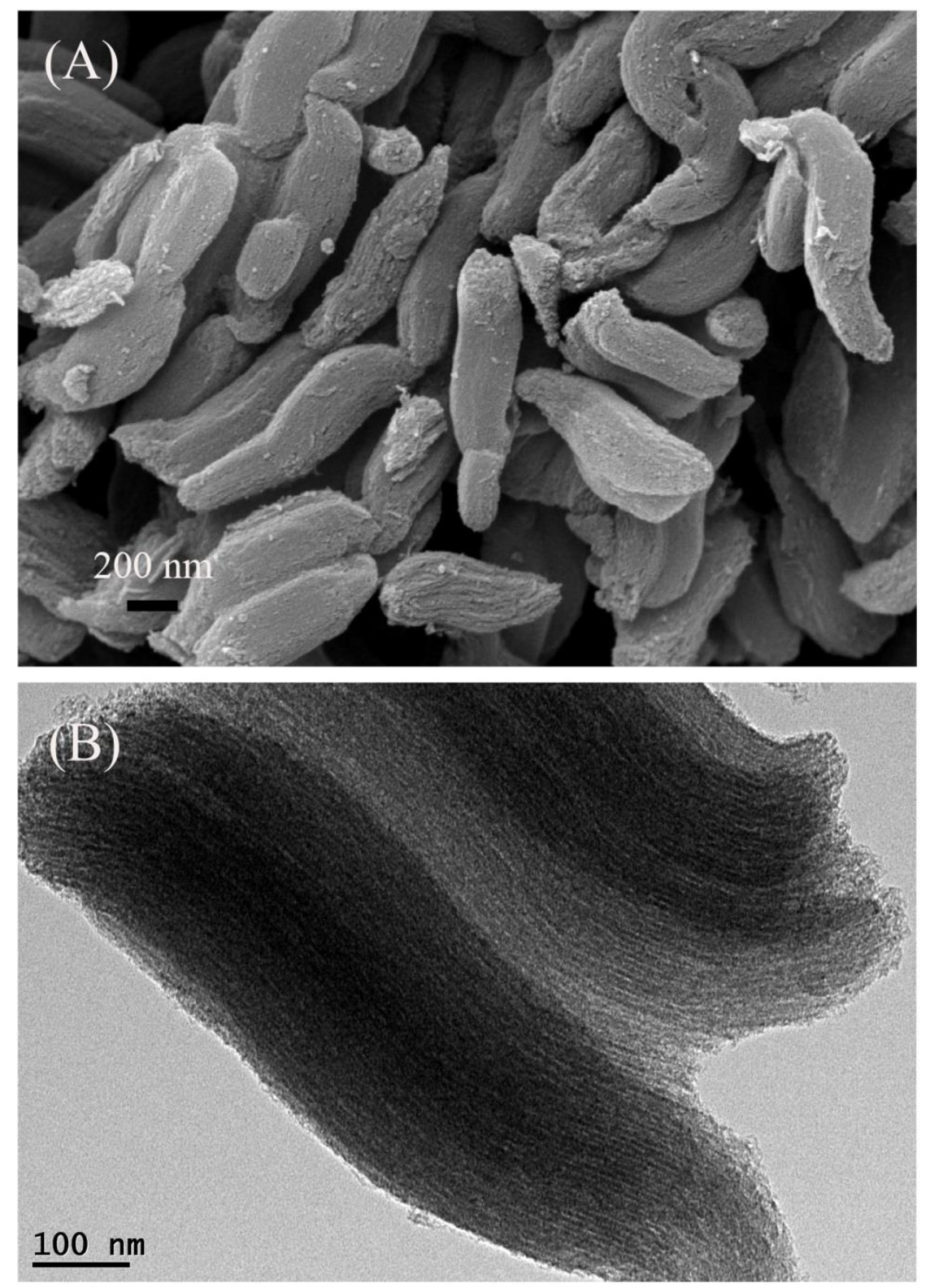

Figure S1. A) SEM and B) TEM images of porous carbon. 


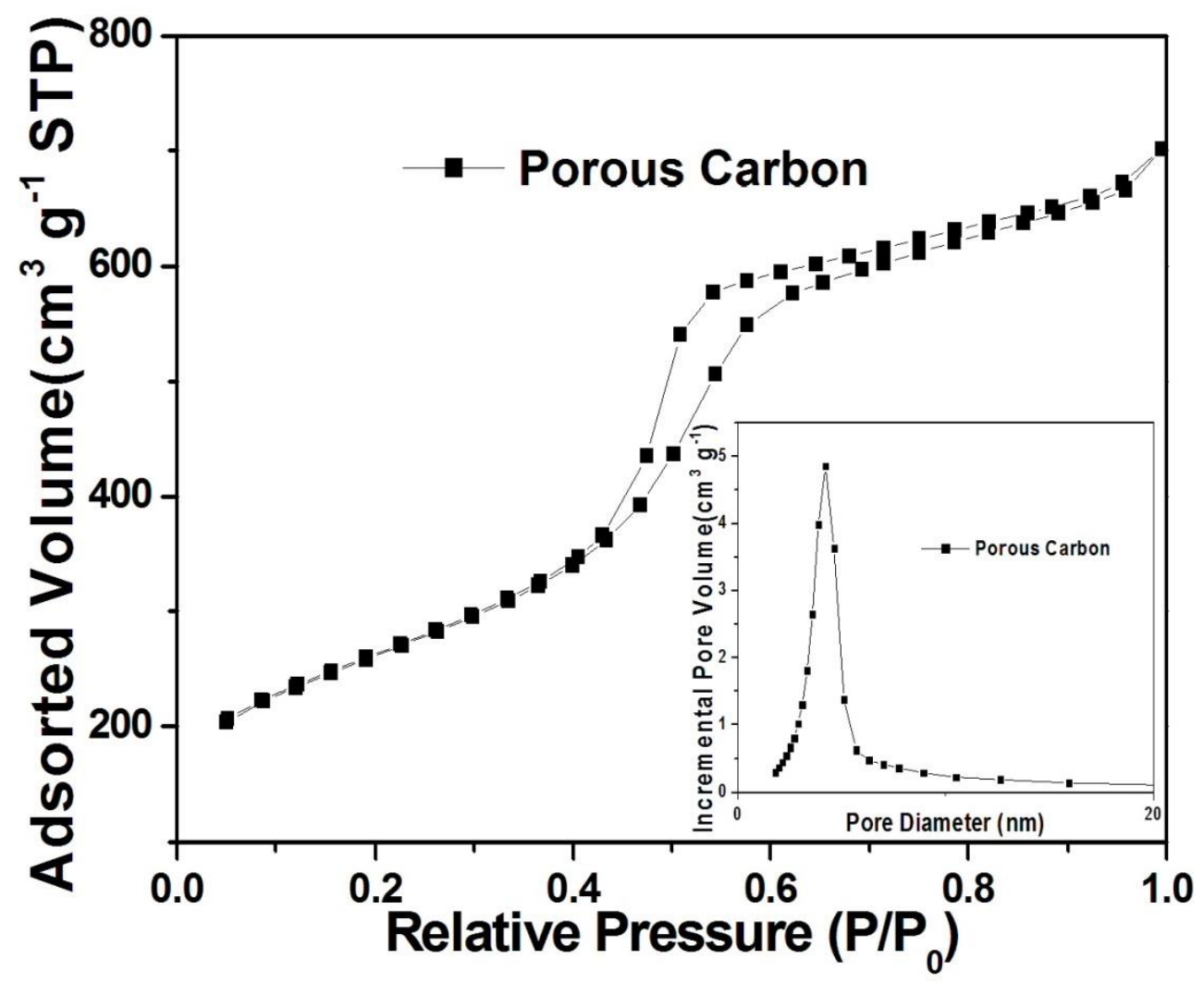

Figure S2. $\mathrm{N}_{2}$ sorption isotherms of porous carbon (inset is the corresponding pore-size distribution). 

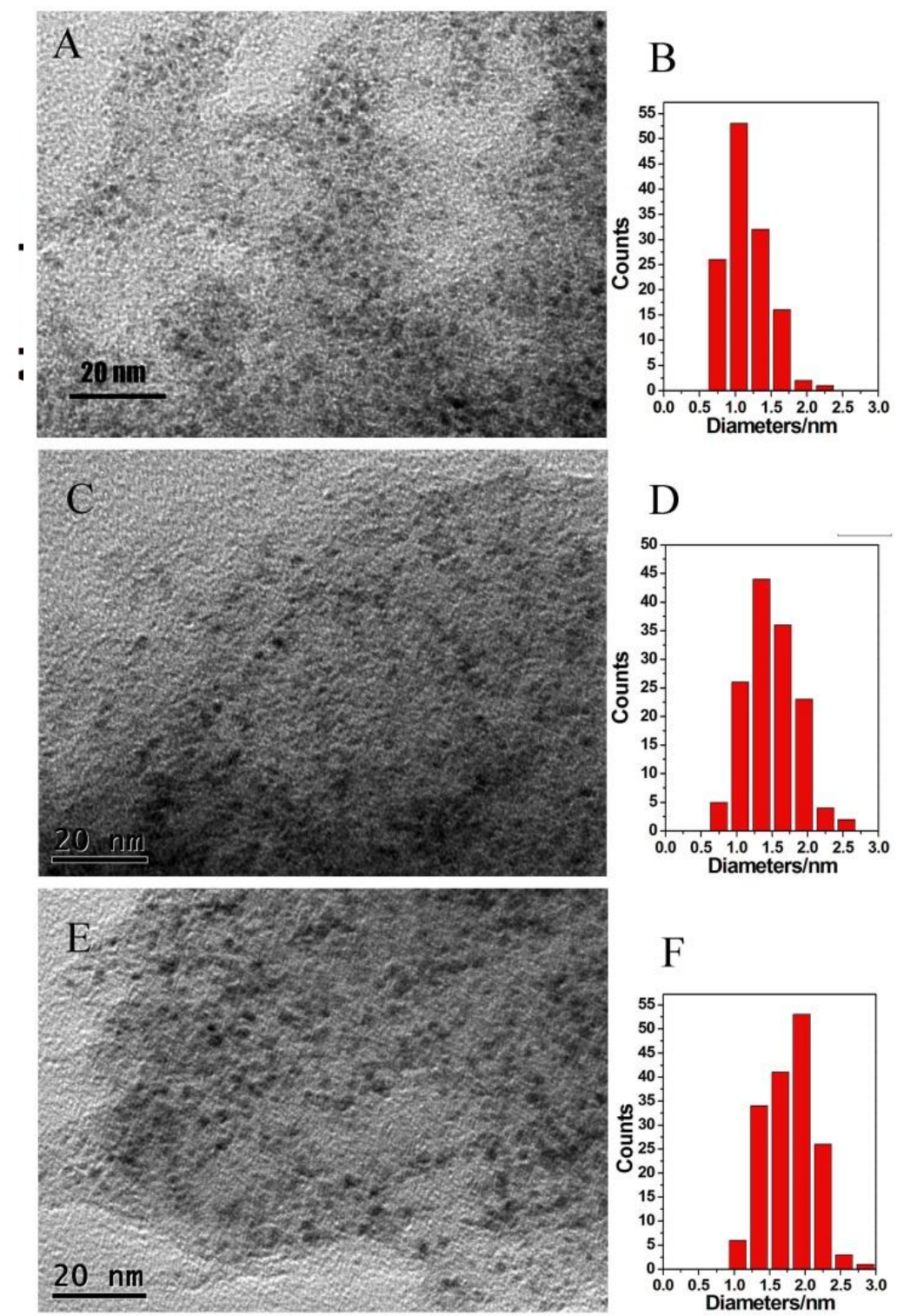

Figure S3. Representative TEM images of (A) $\mathrm{Au}_{25}\left(\mathrm{SC}_{2} \mathrm{H}_{4} \mathrm{Ph}\right)_{18}$, (C) $\mathrm{Au}_{38}\left(\mathrm{SC}_{2} \mathrm{H}_{4} \mathrm{Ph}\right)_{24}$ and $(\mathrm{E}) \mathrm{Au}_{144}\left(\mathrm{SC}_{2} \mathrm{H}_{4} \mathrm{Ph}\right)_{60}$ nanoclusters, with their corresponding core size histograms in panels (B), (D) and (F). The average core diameters were estimated to be $1.10 \pm 0.30 \mathrm{~nm}, 1.20 \pm 0.35 \mathrm{~nm}$ and $1.60 \pm 0.50 \mathrm{~nm}$, respectively. 


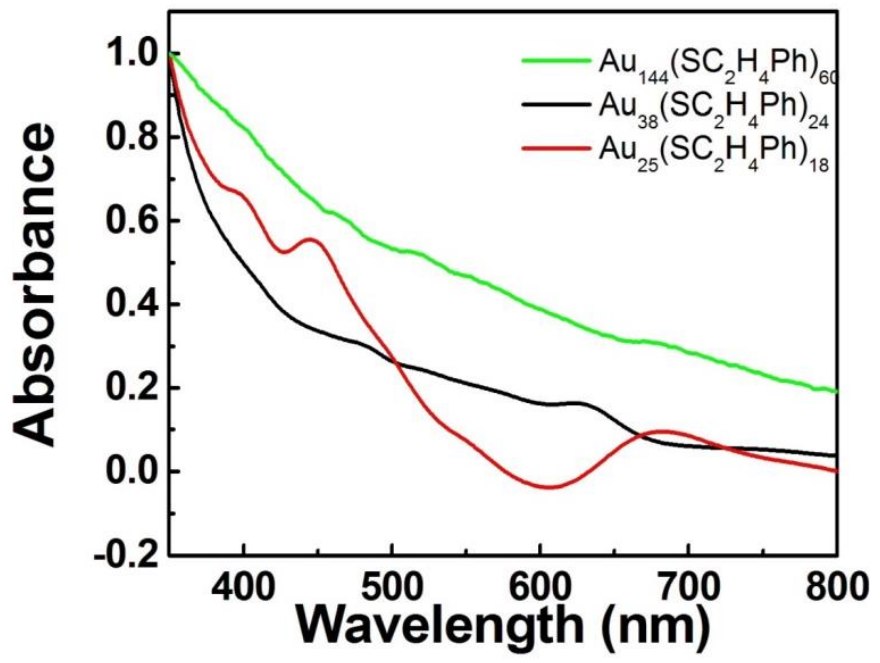

Figure S4. UV-visible absorption spectra of $\mathrm{Au}_{25}\left(\mathrm{SC}_{2} \mathrm{H}_{4} \mathrm{Ph}\right)_{18}, \mathrm{Au}_{38}\left(\mathrm{SC}_{2} \mathrm{H}_{4} \mathrm{Ph}\right)_{24}$ and $\mathrm{Au}_{144}\left(\mathrm{SC}_{2} \mathrm{H}_{4} \mathrm{Ph}\right)_{60}$. $\mathrm{Au}_{25}\left(\mathrm{SC}_{2} \mathrm{H}_{4} \mathrm{Ph}\right)_{18}$ nanoclusters showed distinct peaks at 400,445 , and $680 \mathrm{~nm}$. $\mathrm{Au}_{38}\left(\mathrm{SC}_{2} \mathrm{H}_{4} \mathrm{Ph}\right)_{24}$ nanoclusters showed prominent peaks at 485 and $620 \mathrm{~nm}$. $\mathrm{Au}_{144}\left(\mathrm{SC}_{2} \mathrm{H}_{4} \mathrm{Ph}\right)_{60}$ nanoclusters showed distinct bands at 510 and $700 \mathrm{~nm}$. 

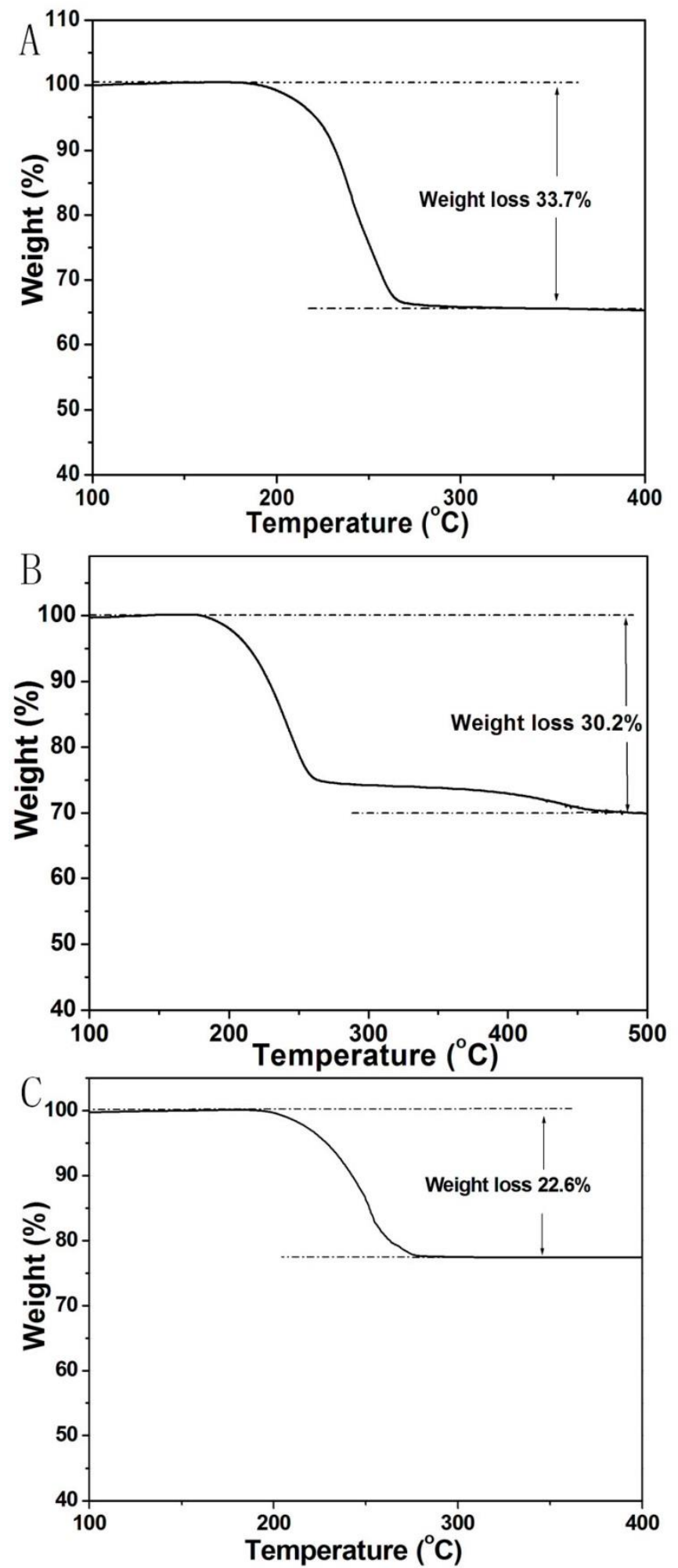

Figure S5. TGA curves of (A) $\mathrm{Au}_{25}\left(\mathrm{SC}_{2} \mathrm{H}_{4} \mathrm{Ph}\right)_{18}$, (B) $\mathrm{Au}_{38}\left(\mathrm{SC}_{2} \mathrm{H}_{4} \mathrm{Ph}\right)_{24}$ and (C) $\mathrm{Au}_{144}\left(\mathrm{SC}_{2} \mathrm{H}_{4} \mathrm{Ph}\right)_{60}$ nanoclusters, where the organic components were estimated to account for about $33.7 \%, 30.2 \%$, and $22.6 \%$ in the nanoparticles, in good agreement with the calculated values of $33.3 \%, 30.5 \%, 22.5 \%$, respectively. 

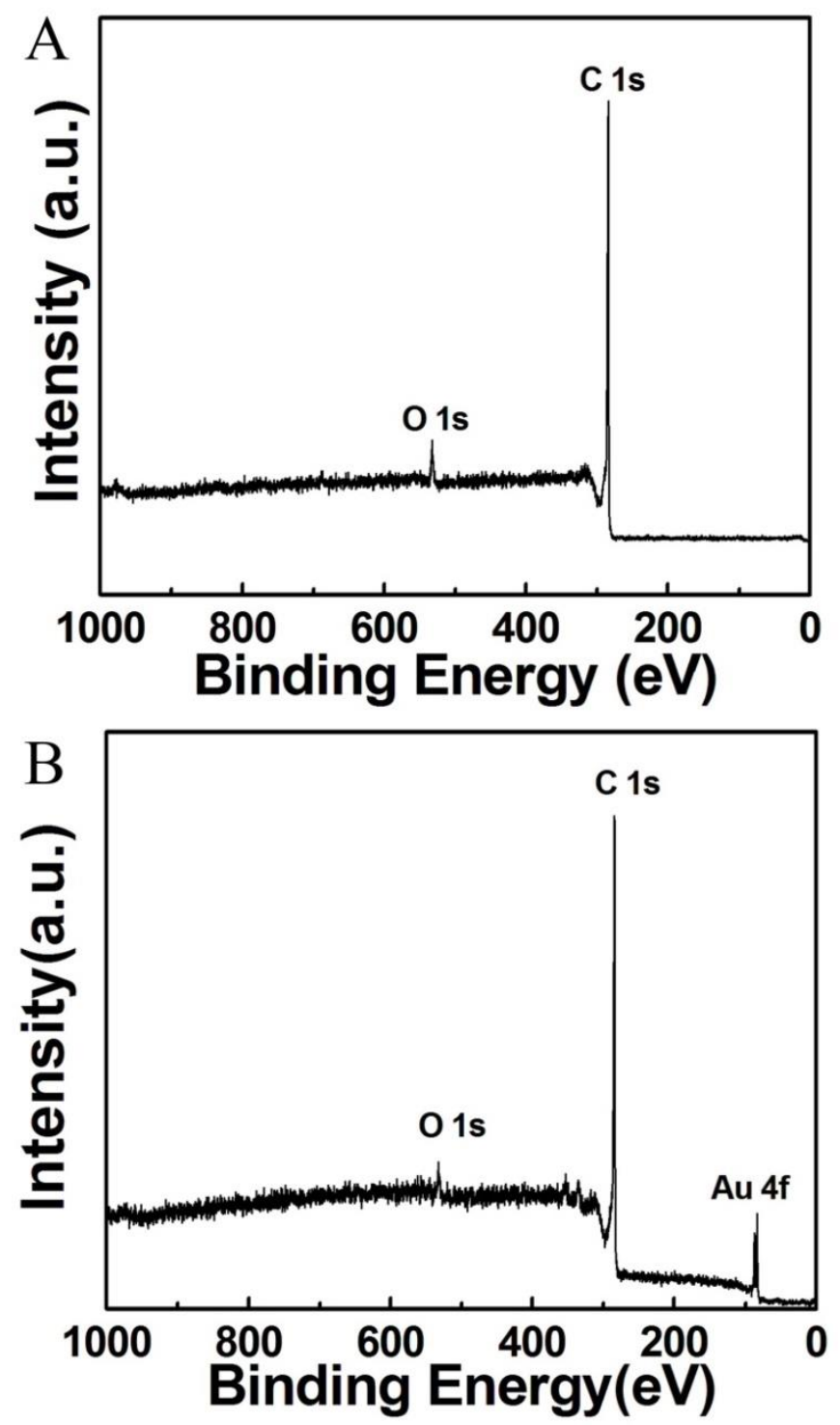

Figure S6. XPS survey spectra of (A) porous carbon and (B) AuPC-1. In panel (B), based on the integrated peak areas, the gold loading was estimated to be 0.8 atom\%. 

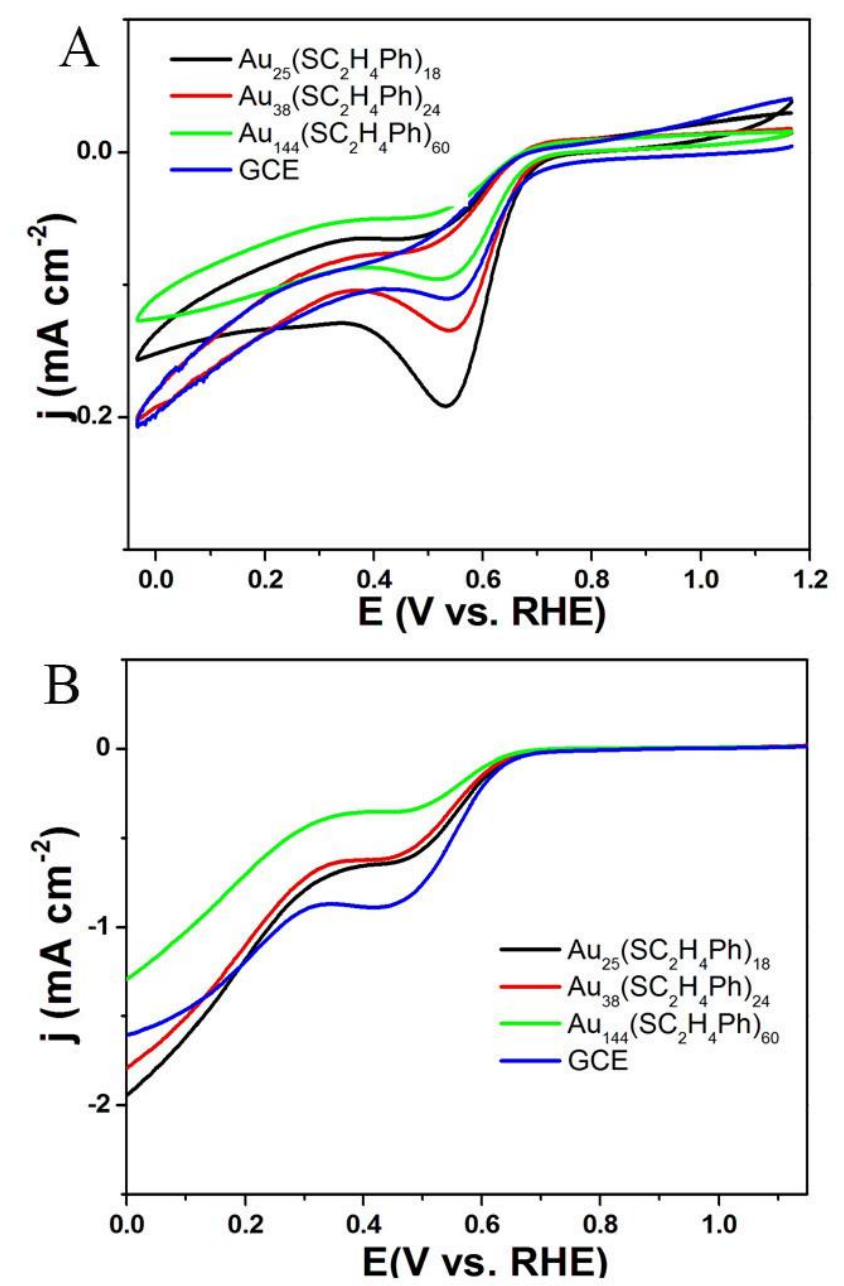

Figure S7. (A) Cyclic voltammograms of GCE, $\mathrm{Au}_{25}\left(\mathrm{SC}_{2} \mathrm{H}_{4} \mathrm{Ph}\right)_{18}, \mathrm{Au}_{38}\left(\mathrm{SC}_{2} \mathrm{H}_{4} \mathrm{Ph}\right)_{24}$ and $\mathrm{Au}_{144}\left(\mathrm{SC}_{2} \mathrm{H}_{4} \mathrm{Ph}\right)_{60}$ in 0.1 $\mathrm{M} \mathrm{KOH}$ solution saturated with oxygen at a scan rate of $10 \mathrm{mV} / \mathrm{s}$. (B) RDE voltammograms of GCE, $\mathrm{Au}_{25}\left(\mathrm{SC}_{2} \mathrm{H}_{4} \mathrm{Ph}\right)_{18}, \mathrm{Au}_{38}\left(\mathrm{SC}_{2} \mathrm{H}_{4} \mathrm{Ph}\right)_{24}$ and $\mathrm{Au}_{144}\left(\mathrm{SC}_{2} \mathrm{H}_{4} \mathrm{Ph}\right)_{60}$ in $0.1 \mathrm{M} \mathrm{KOH}$ solution saturated with oxygen at the rotation rate of $2500 \mathrm{rpm}$. 

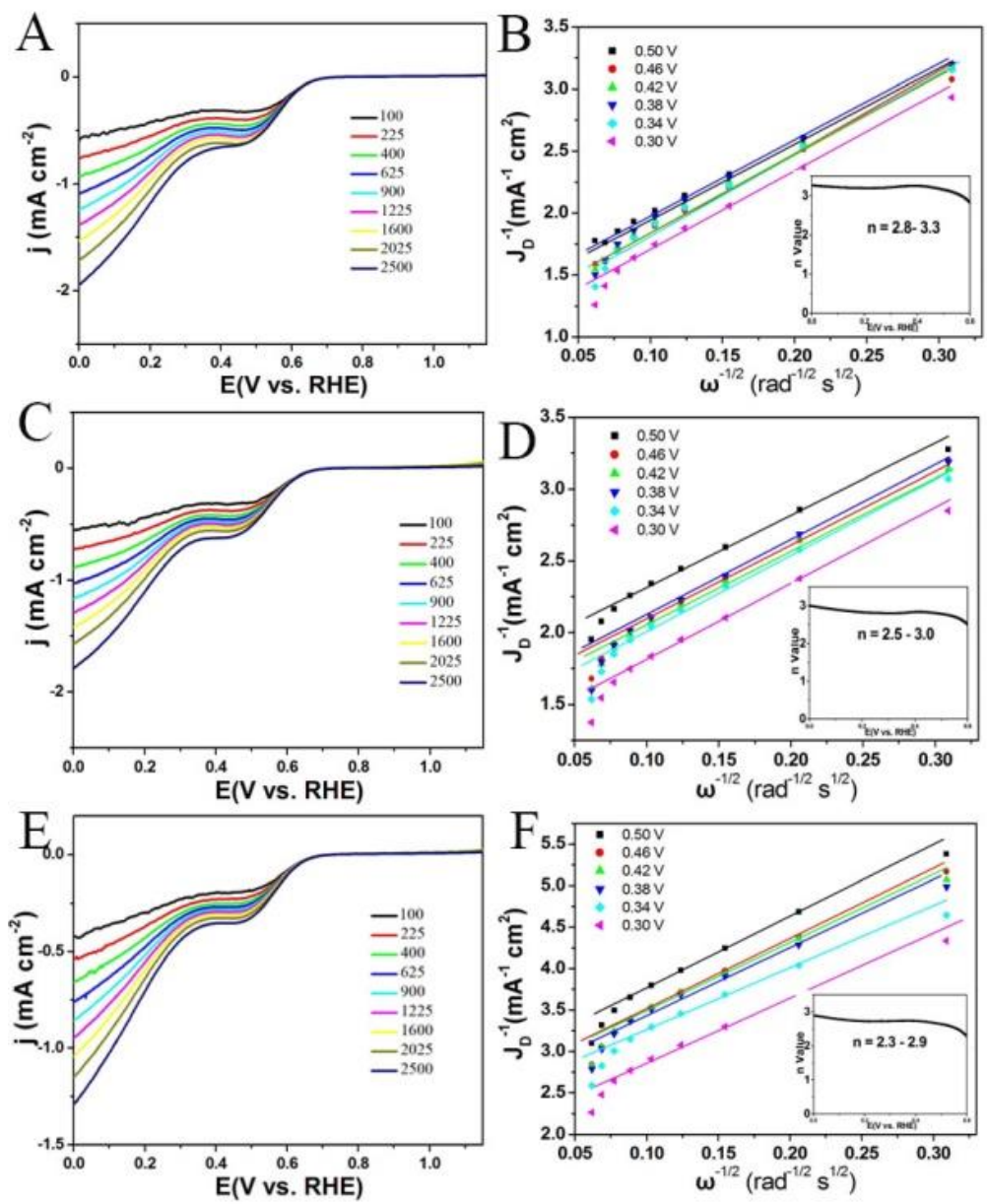

Figure S8. RDE voltammograms and corresponding Koutecky-Levich plots $\left(j^{-1}\right.$ versus $\left.\omega^{-1 / 2}\right)$ of different catalysts in $\mathrm{O}_{2}$-saturated $0.1 \mathrm{M} \mathrm{KOH}$ with a sweep rate of $10 \mathrm{mV} \mathrm{s}^{-1}$ at different rotation rates: (A and B) $\mathrm{Au}_{25}\left(\mathrm{SC}_{2} \mathrm{H}_{4} \mathrm{Ph}\right)_{18,}\left(\mathrm{C}\right.$ and D) $\mathrm{Au}_{38}\left(\mathrm{SC}_{2} \mathrm{H}_{4} \mathrm{Ph}\right)_{24}$ and $(\mathrm{E}$ and $\mathrm{F}) \mathrm{Au}_{144}\left(\mathrm{SC}_{2} \mathrm{H}_{4} \mathrm{Ph}\right)_{60}$. 


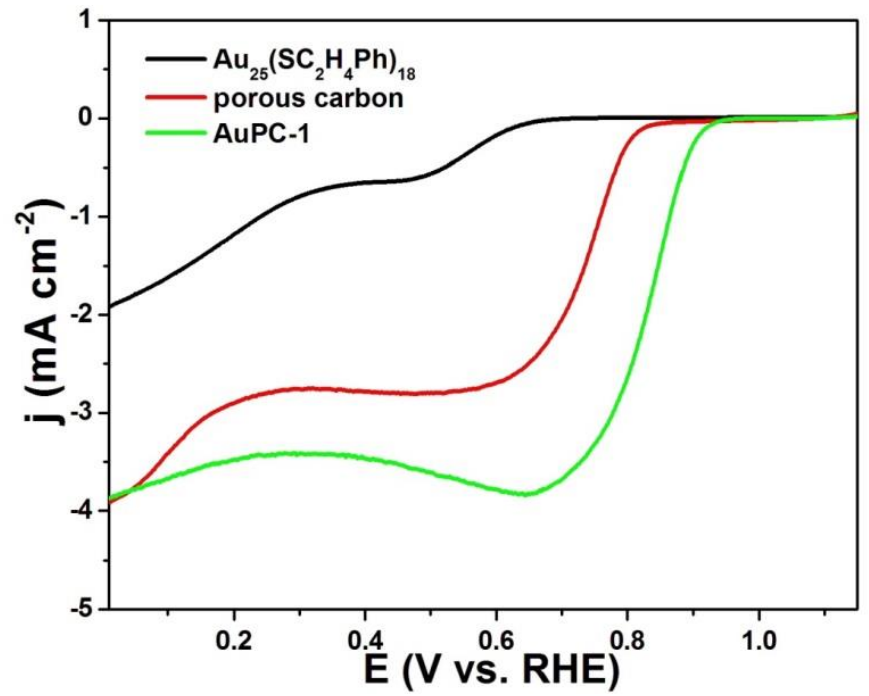

Figure S9. LSV curves for $\mathrm{Au}_{25}\left(\mathrm{SC}_{2} \mathrm{H}_{4} \mathrm{Ph}\right)_{18}$, porous carbon and AuPC-1 in $0.1 \mathrm{M} \mathrm{KOH}$ solution saturated with oxygen at the rotation rates of $2500 \mathrm{rpm}$. 

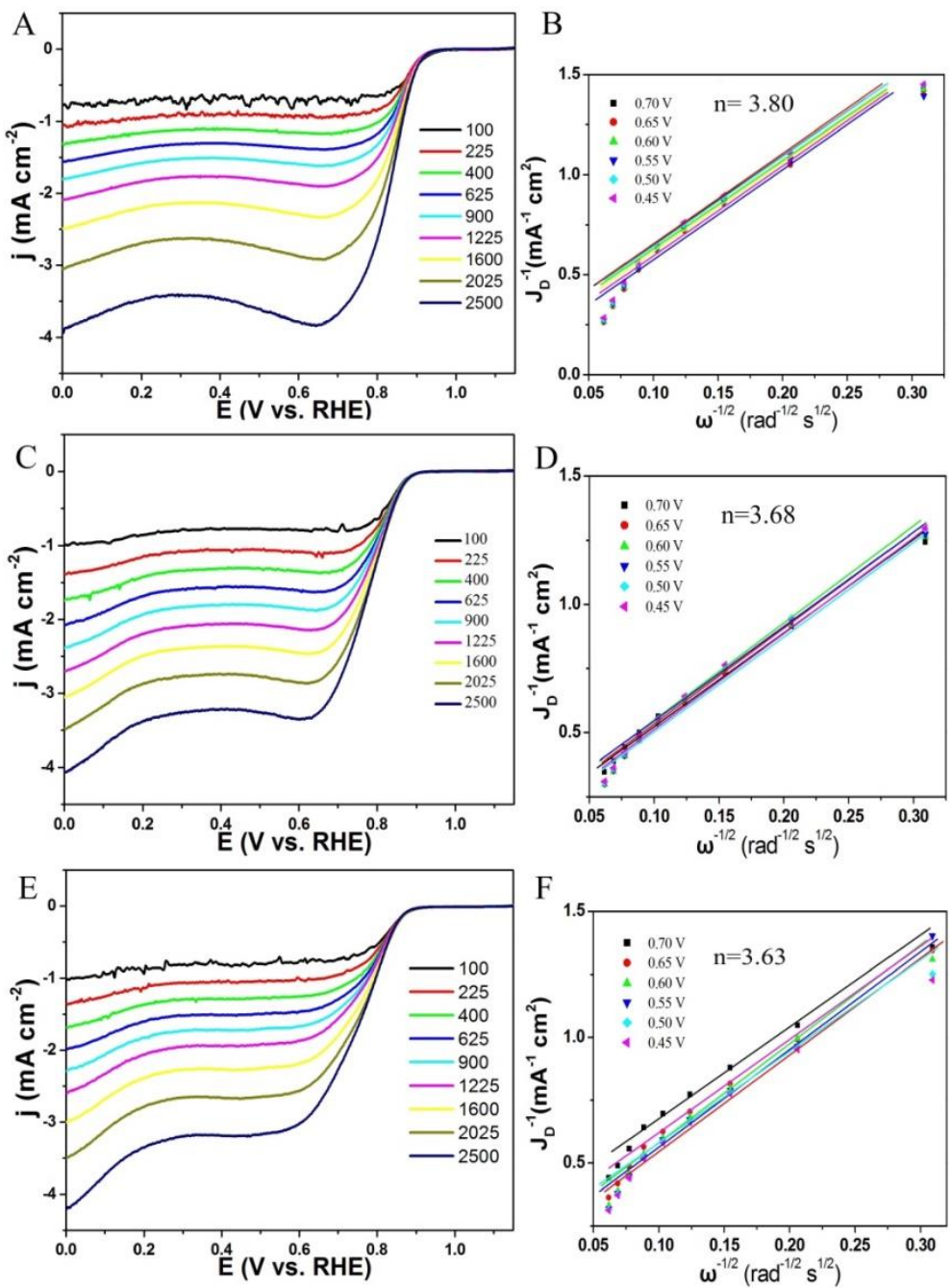

Figure S10. RDE voltammograms and corresponding Koutecky-Levich plots $\left(\mathrm{j}^{-1}\right.$ versus $\left.\omega^{-1 / 2}\right)$ of different catalysts in $\mathrm{O}_{2}$-saturated $0.1 \mathrm{M} \mathrm{KOH}$ with a sweep rate of $10 \mathrm{mV} \mathrm{s}^{-1}$ at different rotation rates: (A and B) AuPC-1, (C and D) AuPC-2, (E and F) AuPC-3. 


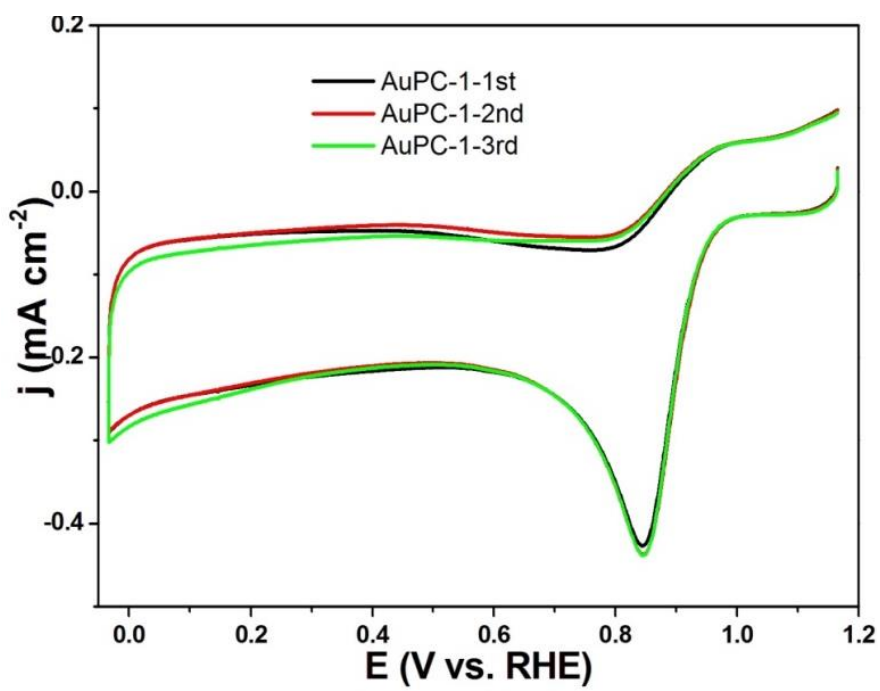

Figure S11. Cyclic voltammeograms of AuPC-1 in $0.1 \mathrm{M} \mathrm{KOH}$ solution after three repeated uses for ORR.

\section{References}

(1) Jun, S.; Joo, S. H.; Ryoo, R.; Kruk, M.; Jaroniec, M.; Liu, Z.; Ohsuna, T.; Terasaki, O. Synthesis of New, Nanoporous Carbon with Hexagonally Ordered Mesostructure. J. Am. Chem. Soc. 2000, 122, 10712-10713.

(2) Wang, L. K.; Tang, Z. H.; Liu, X. J.; Niu, W. H.; Zhou, K.; Yang, H. Y.; Zhou, W. J.; Li, L. G.; Chen, S. W. Ordered Mesoporous Carbons-supported Gold Nanoparticles as Highly Efficient Electrocatalysts for Oxygen Reduction Reaction. RSC Adv. 2015, 5, 103421-103427.

(3) Yao, C.; Chen, J.; Li, M. B.; Liu, L.; Yang, J.; Wu, Z. Adding Two Active Silver Atoms on Au Nanoparticle. Nano Lett. 2015, 15, 1281-1287.

(4) Qian, H.; Zhu, Y.; Jin, R. Size-Focusing Synthesis, Optical and Electrochemical Properties of Monodisperse Au38(SC2H4Ph)24 Nanoclusters. ACS Nano 2009, 3, 3795-3803.

(5) Qian, H.; Jin, R. Controlling Nanoparticles with Atomic Precision: The Case of Au144(SCH2CH2Ph)60. Nano Lett. 2009, 9, 4083-4087. 